\title{
QUANDO FALAMOS DE CUIDADO, DO QUE ESTAMOS FALANDO? ENTREVISTA COM ILZE ZIRBEL
}

\author{
CUANDO HABLAMOS DE CUIDADO, ¿DE QUÉ ESTAMOS HABLANDO? \\ ENTREVISTA CON ILZE ZIRBEL
}

\section{WHEN WE TALK ABOUT CARE, WHAT ARE WE TALKING ABOUT? INTERVIEW WITH ILZE ZIRBEL}

\author{
Carlos Roberto Castro-Silva ${ }^{1}$, Danilo de Miranda Anhas ${ }^{1}$, \\ Karina Rodrigues Matavelli Rosa ${ }^{1}$, Laís Helena Dutra ${ }^{1}$, \\ Lia Thieme Oikawa Zangirolani ${ }^{1}$ e Luciane Maria Pezzato ${ }^{1}$
}

${ }^{1}$ Universidade Federal de São Paulo, Santos/SP, Brasil

\section{Apresentação}

Em um pouco mais de 10 anos de trabalho em ensino, pesquisa e extensão na Universidade Federal de São Paulo - Instituto Saúde e Sociedade, relacionados com as práticas da Estratégia Saúde da Família (ESF), a questão da produção do cuidado tem se mostrado um balizador importante da qualidade dos vínculos estabelecidos no território entre os diferentes atores sociais envolvidos. A atenção para os vínculos acontece devido ao privilegiamento de um olhar para a realidade por meio da lente da intersubjetividade/ afetividade, ou seja, para aquelas características psicossociais que delineiam os modos de sociabilidade e práticas em saúde. A referência da psicologia sócio-histórica e cultural tem contribuído para a compreensão da subjetividade construída a partir da interação dos sujeitos com seu meio social, além do aprofundamento da discussão de processos de politização das práticas em saúde, principalmente sobre a apreensão das relações de poder no território, e as formas de mobilização comunitária, consequentemente, no enfrentamento da exclusão social, destacando o protagonismo de mulheres na saúde e em movimentos sociais. Dessa forma, o texto a seguir apresenta uma conversa-entrevista entre um grupo de pesquisa Laboratório de Estudos sobre a Desigualdade Social (LEDS) e a pesquisadora do campo das Teorias do Cuidado, Ilze Zirbel. O grupo em questão desenvolveu uma pesquisa, denominada: Ética do cuidado e construção de direitos: acolhimento psicossocial em práticas da saúde da família em situações de exclusão social, com financiamento da Fapesp n² 2016/23973-2, com profissionais de saúde, lideranças comunitárias e moradores de quatro diferentes comunidades dos morros e mangues da Baixada Santista, procurando identificar como as pessoas desses territórios compreendiam o cuidado. A conversa, posteriormente transcrita e aqui publicada, levanta questões cruciais sobre a elaboração de um conceito mais robusto de cuidado, tratando de alguns dos problemas enfrentados por quem vivencia o cuidado na prática e por quem o discute no campo teórico: o paternalismo e a opressão presentes nas relações de cuidado; o autossacrifício de cuidadores e cuidadoras; questões de gênero etc. Boa leitura! 


\section{Primeira parte da entrevista: $\mathrm{O}$ que é o cuidado e como defini-lo?}

Equipe do projeto: Como você define cuidado e quais são, na sua opinião, os autores mais lidos Brasil, ligados a esse tema?

Entrevistada: Buscar uma definição para o cuidado não é uma tarefa simples, vou voltar a essa questão posteriormente. Quanto aos autores mais trabalhados no nosso país, acredito que temos dois núcleos que partem de duas bases diferentes: o núcleo que trabalha a partir de questões feministas e aquele que tem feito uso dos textos de Leonardo Boff. Este segundo grupo tematiza o cuidado no contexto da saúde e atrelado a questões ecológicas. Boff (1999; 2005) é um autor bastante lido em meio a grupos populares, muitas vezes atrelados a grupos religiosos também, visto a importância que ele teve junto às $C E B s^{l}$ no Brasil. No meio acadêmico também temos quem trabalhe com os seus textos que, por sua vez, encontram em Martin Heidegger e no mito - ou fábula - da cura seu ponto de apoio e reflexão.

Eu trabalho junto ao primeiro núcleo, o dos estudos feministas. Nele há diversos grupos que focam em variadas direções, incluindo feministas que discutem o tema da Reprodução Social, seguindo um caminho pautado nas questões econômicas e sociais - pontuadas por feministas marxistas e socialistas - até feministas que iniciaram sua caminhada a partir de questões morais e éticas oriundas da Ética do Cuidado (iniciando na Psicologia moral, passando pela Filosofia, Pedagogia e Bioética, dentre outros campos) até desembocar, nas últimas décadas, nas teorias políticas. E foi esse o meu caminho de pesquisa, inclusive. Os dois núcleos de trabalho, feminista e boffniano, por terem se formado de maneiras distintas, não costumam se encontrar. Ainda assim, acredito que possuem pontos de contato a serem explorados.

Há, ainda, uma segunda diferença entre os grupos que trabalham com a temática do cuidado: há quem parte em busca de apoio em textos mais acadêmicos vindo de uma experiência de trabalho de campo ou comunitário (na saúde, na pedagogia, em grupos de mulheres) e quem faça o caminho inverso: está no meio acadêmico, lidando com o tema, e parte em busca de material empírico na realidade social. Aqui também acabo me situando.

A proposta investigativa de vocês, de verificar como certos grupos de pessoas compreendem o cuidado, é bastante valiosa para esse segundo grupo, no qual também me incluo. Isso me faz pensar na filósofa e etnógrafa Annemarie Mol (2008), que se dedica a estudos de caso. ${ }^{2}$

Minha pesquisa é mais teórica. Segui a trajetória das pesquisadoras que se perguntaram, por exemplo, o que as pessoas mobilizam em si mesmas quando passam a raciocinar segundo uma lógica de cuidado. O que chamo de "primeira geração das teóricas do cuidado"s foi a geração que fez um enfrentamento dentro do campo da Psicologia e da Filosofia para defender um assunto considerado menor, desvalorizado, como o das práticas e atitudes de cuidado. Por causa da desvalorização desse tema, a gente nem chegava a focar no cuidado para poder defini-lo de maneira mais acurada. Ninguém investigava. Era algo "de mulher", próprio do universo feminino e uma atividade oriunda de sentimentos como o amor. ${ }^{4}$

Eu costumo trabalhar com epistemologia da ignorância, uma área da Filosofia que afirma ser importante pensar para além daquilo que foi definido como central para o conhecimento. É preciso pensar também naquilo que ficou de fora e perguntar os motivos que levam à não produção de certos conhecimentos ou ao abandono de certos temas. As primeiras pesquisadoras do cuidado seguiram nessa linha e se dedicaram a entender algo que ninguém tinha decidido estudar: as atitudes e práticas de cuidado. E elas fizeram descobertas muito interessantes. 
Aqui surge uma justificativa para a importância da pesquisa acadêmica/teórica sobre o cuidado, efetuada pelas Ciências Humanas. Ela se interessa por aquilo que ainda não é tão evidente como sendo vital para as sociedades. Ela questiona as próprias perguntas que são feitas, assim como as respostas que são dadas. Essas perguntas e essas respostas podem ser diferentes daquelas que vamos encontrar entre as pessoas dispersas pelas comunidades. Por exemplo, as primeiras pesquisadoras da Ética do Cuidado fizeram muitos avanços ao procurarem compreender a forma de operar desse tipo de ética ou comportamento. ${ }^{5}$

Eu achei genial a questão levantada pela primeira geração de pesquisadoras do cuidado e pela

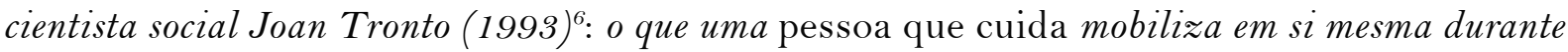
um processo de cuidado? O que entra em funcionamento na sua mente? No que tudo ela precisa pensar antes de agir?

A primeira geração de teóricas, e a segunda também, dedica-se, em especial, a observar a pessoa que cuida. Sempre em diálogo com a pessoa que é cuidada. Elas procuram definir o que é o cuidado e acabam descrevendo as disposições do cuidado: um conjunto de disposições, morais e racionais, envolvidas nessa prática. Elas percebem, por exemplo, que um cuidador ou cuidadora costuma estar atento. Se não está, não percebe a outra pessoa, as necessidades da outra pessoa. Mas isso não basta. Também é preciso se importar. É possível prestar atenção em alguém e não estar "nem aí" para ela. Podemos perceber o problema e virar as costas.

Na prática do cuidado está envolvida a atenção e o ato de se importar. A pessoa ouve, vê e se importa. A disposição seguinte, e necessária, é a de estar disposta a agir, a fazer alguma coisa, para, então, efetuar o raciocínio sobre a melhor maneira de atuar.

Antes das buscas por compreensão dessas práticas, o cuidado era descrito e entendido como algo que acontecia de maneira "natural", ou automática, sem a mobilização dos processos envolvidos com a racionalidade.

Joan Tronto (1993) descreve uma espécie de "passo-a-passo" daquilo que acontece na mente de uma pessoa que cuida. Ela está prestando atenção. Percebe um problema. Se importa e começa a buscar uma solução. Há, nesse processo, vários raciocínios envolvidos. É preciso compreender o que está acontecendo, decidir agir, decidir quem é a pessoa mais apta para efetuar a ação necessária etc.

As pesquisadoras do cuidado investigaram as disposições envolvidas nas atividades de cuidar. E por causa do trabalho delas podemos colocar hoje o cuidado tanto no campo das pesquisas morais quanto das pesquisas políticas. Há, por exemplo, quem defenda o estudo do cuidado como algo pertencente ao campo da "Ética da Virtudes": a pessoa precisa ter ou desenvolver um conjunto de qualidades para que, então, seja considerada uma cuidadora. Para outros, a questão é diferente: estaríamos falando de um conjunto de raciocínios de tipo moral, e não de qualidades. Por fim, depois de trinta anos de discussões e pesquisas, temos o grupo que afirma ser o cuidado uma necessidade e um valor social muito mais amplo e central do que se admitia. Trata-se de algo tão fundamental que essa pode ser uma das razões pelas quais vivemos em sociedade: receber e fornecer cuidados básicos e essenciais.

Essas primeiras teóricas, que também eram feministas, tiveram de abrir caminho, tiveram de brigar e afirmar: vocês estão negligenciando algo central à humanidade porque o estão considerando inferior, secundário..., já que o entendem como "coisa de mulher", "algo natural" e relegado "ao âmbito da casa e das emoções", em meio a uma cultura que supervaloriza o político e o que considera masculino. 
Voltando ao material produzido pela pesquisa de campo do projeto de vocês. Vejo que as pessoas da comunidade, quando definem o cuidado, ou como gostariam de ser cuidadas e como cuidam, produzem um material que deveríamos usar para verificar ou ajustar aquilo que estamos definindo como cuidado ou como o raciocínio do cuidado. Assim, poderíamos ver se isso vai ao encontro daquilo que as pessoas gostariam ou compreendem que é um bom cuidado. É comum ouvirmos, por exemplo, coisas do tipo: "eu não fui bem cuidado" ou "fui mal-cuidada". Temos expressões desse tipo aparecendo o tempo todo. É possivel levantar um material com essas características e examiná-lo à luz dos nossos conceitos.

Há, ainda, uma outra questão. Se tivermos um conceito de cuidado "robusto", ele pode nos auxiliar a pensar e questionar os modelos de cuidado existentes, quando eles são fracos ou falhos. Vou dar um exemplo. Quando se diz que um homem "cuida da família", no que estamos pensando? Que ele a "protege" e "coloca comida na mesa" - é trabalhador e "paga as contas". Alguns questionamentos de mulheres começam a nos mostrar que talvez isso não seja o mesmo que um bom cuidado. Mais do que isso: pode haver por trás dessa prática um outro tipo de prática que exige a sujeição e a opressão das mulheres e das crianças. Pode estar escondida nela uma justificação da violência doméstica: se eu me comporto como um homem trabalhador, vocês devem me obedecer e se submeter às minhas ordens e desejos. Eu não classificaria isso nem mesmo como cuidado, muito menos como um bom cuidado. Se a proteção e a manutenção da vida das pessoas implicam sujeição e obediência, sob ameaça de agressões verbais ou físicas, essas são práticas de violência, e não de cuidado. ${ }^{7}$ No entanto, comumente se diz que essa é a maneira de um homem cuidar da sua família. Milhares de meninos são educados para pensar que, se forem bons trabalhadores, serão bons maridos e pais e, em troca, podem exigir uma série de coisas. Do outro lado, temos milhares de mulheres que se submetem a maus-tratos, relações sexuais indesejadas, humilhações... e que retiram seus boletins de ocorrência após terem tido a coragem de fazê-los, porque os homens com os quais convivem "são honestos e trabalhadores". Há uma confusão muito grande relativa às atividades de cuidado partilhadas doméstico-familiar, atreladas aos papéis de gênero.

No fundo, circula em nosso entorno a noção de que há formas de cuidar que podem não ser realmente boas ou que exigem um preço elevado para quem cuida ou mesmo para quem é cuidado. E não falo de valores econômicos, o que também é preciso considerar seriamente, mas falo dos arranjos e práticas envolvidas nas relações entre as pessoas interligadas na rede de cuidado. Sabemos que, em muitas circunstâncias, relações nocivas de cuidado são necessárias, porque é a única coisa que se tem. Às vezes, aquela pessoa acha que a maneira como ela cuida da outra está boa, mas para a outra pessoa não é o que ela esperava ou o que precisava e desejava.

Podemos ainda falar de outras relações. Podemos falar do cuidado exercido por mulheres para com outras mulheres ou familiares, do cuidado disponibilizado por instituições, voltado para indivíduos ou comunidades, e que não são bons, ainda que pareçam ser. As coisas são confusas. Ao mesmo tempo que temos essa noção de que há maneiras ruins de cuidar, também pensamos que o cuidado sempre é bom. E pode não ser. Além disso, "não cuidar" também pode ser um tipo de cuidado. Depende das circunstâncias.

Equipe do projeto: Pode ser que cuidar seja estar o tempo todo ao lado da pessoa que precisa de algo: levando isso, levando aquilo, dando a medicação. Mas, para outros, pode ser que o cuidado se manifeste no ato de estar presente, sem precisar agir de uma maneira subserviente: se está ali e, se a pessoa precisa de algo, ela indica. O cuidado se dá sempre em uma relação: a de quem está sendo cuidado e de quem cuida, ou vice-versa. E as pessoas envolvidas podem ter uma visão completamente diferente, uma da outra, do que é o cuidado. Há quem não queria ser cuidado, inclusive. Pode acontecer. 
Por melhor que seja a intenção de quem cuida, pode não estar respondendo às expectativas daquele que é cuidado.

Equipe do projeto: E tem também a linha mais biomédica do cuidado. No nosso trabalho de campo, fomos dando algumas adjetivações ao cuidado. E é bem interessante. Encontramos vários tipos, inclusive o não cuidado.

Entrevistada: No campo teórico tentamos pensar e tornar o mais preciso possível algum conceito, como o que estamos tentando fazer com um conceito de cuidado. Talvez não consigamos encontrar essa definição precisa. De qualquer forma, parece que há uma imagem idealizada do cuidado. Um bom conceito pode auxiliar a confrontar a realidade. Então, pode acontecer de, nas falas das pessoas, o cuidado ser identificado com uma série de coisas que não se encaixariam com um bom cuidado. São atitudes que parecem muito com o ato de cuidar, mas o resultado não é o que estaria de acordo com um bom cuidado, que visa sempre ao bem das pessoas envolvidas na rede de cuidados.

Voltando mais uma vez para o material apresentado no relatório de vocês, atrelado às unidades de saúde. Há a parte que fala da não participação de uma determinada comunidade das atividades propostas para ela. Será que ela não identificou aquilo como uma "aparência de cuidado" e, no fundo, ela tem uma noção de que tem "coisa melhor"? Às vezes, numa determinada unidade, as pessoas estão lá e falam bem daquele lugar. Aparentemente, a mesma coisa está sendo feita em outra unidade/comunidade, mas as pessoas não estão querendo ir. Elas não estão se sentindo confortáveis lá. Por quê? As práticas parecem as mesmas, mas as atitudes podem ser outras. Tanto de quem cuida como do grupo que recebe aquele atendimento. Pode não ser uma "comunidade que é arredia", mas uma comunidade que tem a impressão de que há algo faltando naquela prática. Desconfia-se de que aquilo não seja um "verdadeiro cuidado", mas "outra coisa".

Muitas vezes, as pessoas que cuidam assumem uma postura mais técnica, e não é isso que a comunidade ou a pessoa quer. Outras vezes, as pessoas que recebem cuidados querem exatamente uma postura mais técnica. Há muita variação. Por isso, cada situação, cada comunidade, cada pessoa envolvida, precisa ser levada em conta na sua especificidade. Até podemos ter um modelo básico a seguir, mas muito do que está nas "entrelinhas", nos bastidores, no subjetivo, precisa ser levado em conta também.

Estamos chamando quase tudo de cuidado. Esse é outro problema atrelado à falta de definição. Por isso aparece, na linguagem, a tentativa de sermos "mais precisos" e precisas. Às vezes a gente ouve as pessoas tentando definir "melhor" o cuidado e aparecem expressões como "cuidado de verdade", "bom cuidado" etc. A primeira pesquisadora da ética do cuidado, Carol Gilligan, chamava de "cuidado maduro" aquilo que ela considerava ser um grau de maturidade nas práticas das mulheres que deixavam de se sacrificar e incluíam a si mesmas nos seus raciocinios de cuidado.

Uma coisa a pensar é: como encontrar uma boa cuidadora, um bom cuidador? Alguém que vá exercer bem as atividades de cuidado, sem sacrificar a si mesma/o? O que move nessa pessoa? O que acontece nela que as ações que pratica são reconhecidas como "boas", "corretas", "cuidado de verdade”? Parece que algumas pessoas desenvolvem determinadas características. Elas captaram, elas estão antenadas para a realidade que as cerca de tal maneira que conseguem devolver algo para essa realidade de uma maneira que podemos chamar de "melhor". Não quero desqualificar o trabalho das que não estão assim tão antenadas ou que não conseguem responder do mesmo modo. E nunca podemos esquecer que essa também é uma questão de treino. A maioria das pessoas adultas que tiveram de cuidar de uma pessoa agudamente dependente - como um bebê, que nem consegue se comunicar ainda - não sabiam como fazer. Essa também é uma conclusão das pesquisas: não estamos falando de algo "nato", que nasce com a pessoa. Trata-se de um aprendizado. 
Esse é um outro ponto a ser levado fortemente em conta: o que diz respeito ao "treino" ou às práticas de cuidado. Assim como a primeira geração de pesquisadoras tentou entender o que acontece "dentro" da pessoa que cuida, temos um autor que faz o exercício de pensar o cuidado sem ter de apelar para sentimentos. Daniel Engster (2007), também cientista social, como Joan Tronto, faz uma coisa muito legal e muito interessante, que causa um certo mal-estar, inicial: ele escreve um livro inteiro argumentando que não precisa movimentar nenhum tipo de emoção para defender o cuidado com um valor politico central. Por que ele faz isso? Para poder dizer que o cuidado é uma questão profundamente política e que deveria ser pensado como tal, e não como algo reservado para o privado ou ao encargo de apenas uma parte da população, as mulheres. E ele consegue atingir o seu propósito. Para ele, as questões de cuidado - distribuição dos seus benefícios e responsabilidades - são questões de justiça e são a questão central para a justiça social.

\section{Segunda parte da entrevista:}

\section{Os objetivos do cuidado e os problemas do paternalismo e da opressão}

Entrevistada: Essa questão do "mau cuidado" também é abordada no campo de pesquisas. Um dos problemas que aparece é o do paternalismo. Há práticas que parecem boas, protetivas, mas impedem o crescimento da outra pessoa. As pesquisadoras do campo da deficiência apontam para isso, assim como as feministas. Há cuidado que tolhe ou infantiliza a pessoa que está sendo cuidada! Há práticas de cuidado de tipo paternalista, que impedem o crescimento, desenvolvimento e liberdade das pessoas envolvidas. Quem discute e pensa o tema consegue afirmar que um cuidado mais maduro, o bom cuidado, consegue eliminar o paternalismo. Aqui estamos entrando na área não mais das disposições do cuidado - dos aspectos presentes em um bom cuidador ou cuidadora - mas no dos objetivos do cuidado como uma maneira de nos auxiliar na produção de um conceito robusto. O foco dos objetivos do cuidado está na pessoa que vai ser cuidada. Temos então um foco na pessoa que cuida, no que acontece dentro dela, e outro na pessoa a ser cuidada. Sem esquecer que esses focos têm a intenção de descobrir coisas, mas que o cuidado se dá, geralmente, em uma rede de relações na qual a posição dos agentes pode ser, e frequentemente é, intercambiável. Todos nós precisamos de cuidados ao longo da nossa vida, de diversas maneiras, e todos cuidamos de pessoas ao nosso redor, de diversas maneiras. Esses estudos têm auxiliado quem efetua atividades remuneradas de cuidado, como pedagogas, agentes de saúde, cuidadoras de pessoas idosas, crianças, pessoas com deficiência etc.

Então, se o foco está na pessoa a ser cuidada, o objetivo de quem cuida há de ser o bem-estar $e$ o desenvolvimento dessa outra pessoa. E aqui encontramos como objetivo a autonomia dela, de alguma maneira. ${ }^{8}$ Ter o olhar posto no desenvolvimento da autonomia da pessoa que está sendo cuidada é uma forma de evitar o paternalismo. Viabilizar as condições materiais, emocionais e psíquicas para que ela possa fazer suas próprias escolhas e implementá-las faz parte dos objetivos de um bom cuidado.

A maioria de nós mulheres, mães e pais, temos a tendência de exercer um cuidado paternalista. Temos de aprender, ao longo da vida, a deixar nossos filhos e filhas seguirem caminhos escolhidos por eles e elas. O paternalismo é um dos perigos que ronda as atividades de cuidado, tanto para quem trabalha com um cuidado técnico quanto para quem exerce cuidado em meio a vínculos afetivos.

As relações de opressão são ainda piores que o paternalismo, e muitas vezes estão associadas a ele. Para pensar opressão e cuidado, o campo de estudos sobre a deficiência ${ }^{9}$ tem nos ajudado muito. Há grandes pesquisadoras e pesquisadores nesse campo e que estão produzindo material 
muito significativo. Eu gosto muito da filósofa Anita Silvers. Há uma discussão dela (Silvers, 2015) sobre as pessoas com deficiência, ou idosas, que não querem ser cuidadas por alguém da família. A discussão toca nos temas da opressão, do cuidado institucionalizado e das questões familiares. Ao tratar da questão da deficiência, muitas vezes podemos estar falando de pessoas adultas e saudáveis, mas que são tratadas por seus familiares como se fossem crianças ou totalmente incapacitadas. A relação que a família tem com elas pode ser opressiva, ou elas sentem essa relação como opressiva. Estamos falando de pessoas que vão precisar a vida inteira de uma série de cuidados. Nessa situação, elas podem preferir um cuidado profissional e até mesmo um cuidado mais técnico do que aquele que é proporcionado por uma pessoa de sua rede afetiva, uma vez que esse cuidado pode apresentar, facilmente, características paternalistas. Elas querem se livrar do tipo de relação que tinham dentro da família. Há uma infantilização da pessoa com deficiência, e elas não suportam mais isso. Nessas circunstâncias, poder contratar alguém ou ter uma política pública que as contemple - com empregos ou benefícios salariais que permitam decidir quem vai cuidar delas pode resultar na saída dos espaços e relações que as oprimem.

Equipe do projeto: Qual seria o objetivo principal do cuidado?

Entrevistada: O objetivo mais básico é manter a vida da pessoa que é cuidada. Esse é o mais básico. E eu não preciso ter, necessariamente, afeto envolvido nas atividades, ou em muitas delas, para garantir isso. Ter as necessidades básicas supridas, ter onde dormir, estar abrigada, de banho tomado, ter alimento ... são necessidades básicas, e não podemos desqualificar as atividades que garantem isso, dizendo que não são cuidado. Um cuidado técnico também é cuidado e há pessoas que vão precisar desse tipo de cuidado, e vão preferi-lo.

Eu dei exemplo das pessoas com deficiência, mas as pessoas idosas passam por isso também. Muitas não querem que os filhos cuidem delas. Às vezes a relação familiar não foi boa. A pessoa pode, na fase adulta avançada, ter visto que na vida dela a relação que teve com os filhos não foi boa, e que isso tem a ver com a maneira que ela lidou com os filhos. Ela pode até mudar ou ter mudado. Mas, ainda assim, mudar 20, 30, 40 anos de relacionamento com os filhos não é uma coisa simples. Então, muitas pessoas idosas também não querem ser cuidadas pelos seus familiares porque estabeleceu-se uma relação de opressão, ou de desprezo, de desrespeito, dos mais jovens para com elas.

O tema das atividades de cuidado é a terceira grande linha de pesquisa e de trabalhos da Ética do Cuidado. A primeira foi a das características da pessoa que cuida; A segunda foi a dos objetivos do cuidado; $E$ a terceira foca nas atividades necessárias.

É possível identificar certas atividades como sendo de cuidado, ainda que elas estejam desvinculadas, por exemplo, de uma parte das aptidões ou disposições que identificávamos como importantes para um bom cuidado. No campo da prática, há a questão da aceitação por parte da pessoa que recebe cuidados. Ela precisa ser respeitada. Posso afirmar para ela que aquilo que quero fazer é necessário, como dar um banho, uma medicação..., mas pode ser que ela não queira ou não queira fazer isso essa semana, este mês. Um dos elementos do cuidado é a disposição: estar disposto a dar ou a receber cuidados.

Há muitas coisas envolvidas, e os estudos só crescem e avançam. Já temos alguns tipos de classificação. Como as de que a pessoa que cuida tem certas características e mobiliza certas disposições morais e racionais, que um bom cuidado tem certos objetivos centrais e que ele envolve inúmeros tipos de atividades. Tudo isso nos ajuda a criar um conceito ou uma definição do que é cuidado e tudo o que ele pode envolver. 
Equipe do projeto: Já se tem uma definição mais teórica do cuidado, então?

Entrevistada: Temos uma ideia geral do que poderia fazer parte de uma definição mais teórica do cuidado, ou de um bom cuidado. Tenho três coisas em mente, no momento. A primeira delas é: o cuidado tem que ser dialógico ou dialogal. Apesar disso parecer óbvio, não é algo sempre possível, como é o caso da interação com pessoas com deficiência mental grave, ou com recém-nascidos. Ainda assim, é um elemento central. É necessário o diálogo, para o bem de quem cuida e de quem é cuidado. Além disso, o cuidado é sempre exercido em uma rede de relações. Costumamos falar da pessoa que cuida e da que é cuidada, porque pensamos muito na questão da saúde, mas a rede de cuidados é muito ampla e não está presente apenas no campo da saúde. Então, o cuidado precisa ser dialógico. Mesmo quando focamos no caso da saúde (ou da pessoa idosa, do recém-nascido, da criança em fase escolar, da pessoa com deficiência...) há o lado de quem tem a técnica, a aptidão, os objetivos etc. $E$ do outro lado há um outro ser humano, que é completo, inteiro, que tem seus próprios desejos e sua própria visão de mundo ou a está formando. É preciso diálogo. Um diálogo que inclui respeito, dos dois lados (e dos outros lados envolvidos, quando há mais pessoas interagindo).

$\mathrm{Na}$ bioética discute-se o problema da pessoa que precisa de cuidados e que não pode decidir sozinha sobre eles. Nós temos de ouvi-la, mas às vezes é necessário negociar ou começar um diálogo que será longo, porque a pessoa não quer aquele tipo de cuidado que está sendo oferecido a ela. Não quer tomar a medicação, ou não quer fazer fisioterapia, por exemplo. Ela preferiria outra coisa. Aí o olhar técnico tem que entrar na negociação e dizer: "mas a consequência da sua negação pode ser não se recuperar" etc. Mas ela não gosta, aquilo causa dor. Ela quer apenas que fiquemos com ela e acredita que tudo vai passar, de alguma maneira, ou já não se importa mais. Então, é preciso negociar pois o resultado do que ela deseja pode ser muito mais sério, ainda que o cuidado possível seja muito ruim (como é o caso de uma quimioterapia). É muito complexo. Como você vai explicar que a consequência de ela não aceitar determinados cuidados agora pode significar uma antecipação da morte?

Há, ainda, outra área desafiadora, discutida pela bioética (há várias, na verdade): a da eutanásia. A questão dialogal nem sempre é fácil e nos coloca sempre no dinâmico campo da autonomia e das relações de forças que podem estar operando nele. Nos países em que a eutanásia é permitida como possibilidade de escolha da pessoa consciente, o diálogo também é longo até poder chegar ao ponto em que uma morte digna possa lhe ser autorizada e oferecida. É preciso ter noção se aquilo que ela está decidindo é sob o efeito de uma depressão, de uma dor insuportável e sem tratamento, ou de um plano de vida que ela tem e que já percebeu que não vai dar em nada. Para essa negociação, é preciso pessoas com experiência de um cuidado maduro.

O cuidado, por fim, é um conceito e um conjunto de práticas e disposições complexas.

Essa autora que citei anteriormente, Annemarie Mol (2008), é uma das pesquisadoras que nos diz que podemos falar de tudo isso que estamos falando, mas, no final, temos de dizer que nós não temos um conceito fechado e não queremos ter. Porque é em meio a uma realidade social complexa que estamos pensando o cuidado e já há vários caminhos sendo pensados e vários conceitos. Por que há isso? Porque cada caso é um caso. E ela diz isso dessa maneira nos textos: que podemos ter um conceito, mas ele precisa permanecer aberto, porque vai ser no diálogo de caso por caso que poderemos afirmar coisas como: "nesse caso, o melhor a fazer é não fazer nada". Ou: "nesse caso, o melhor a fazer é não dar ouvidos a pessoa que se nega a ser cuidada."

Equipe do projeto: Sim! Você fala da autonomia de uma pessoa que está profundamente deprimida, mas ela pode não estar em condições de exercê-la. Ela não está na sua plenitude. Veja a pessoa com demência senil, por exemplo. Para um leigo, de repente, não é possível saber isso, se ela está ou não nessa condição. Então cada caso vai ser um caso. 
E vai depender muito desse repertório do cuidador para chegar a uma decisão, para escolher um caminho.

Equipe do projeto: Eu fico pensando: E no caso daquela pessoa que está acamada, numa situação extremamente vulnerável e quem cuida dela é uma pessoa que às vezes até a agride. Isso não seria um cuidado?

Entrevistada: $O$ caso da pessoa que está em depressão talvez até seja facilmente identificado. E acredito que é fácil uma relação assim descambar para a violência (psicológica ou mesmo física, dependendo de como essa relação foi constituída ou das pessoas envolvidas nela) diante dos mal-entendidos sobre a própria depressão. É fácil da pessoa que observa dizer: "não, não posso levá-la em conta porque ela não sabe o que está dizendo e não sabe o que está fazendo". É o argumento que às vezes é usado em relação às pessoas com deficiência mental (ou idosas) quando se negam a tomar banho ou a uma série de outras coisas. Facilmente diz-se que ela não sabe onde ela está. $E$ aí entram as práticas opressivas, violentas. $E$ a pessoa com depressão pode ser um alvo fácil para uma prática violenta. Realmente, o cuidador ou a cuidadora precisaria ter consciência de que é muito fácil escolher o caminho da violência. Muitas relações de cuidado descambam para isso. E ela tem várias formas!

\section{Parte três da entrevista:}

\section{A associação do cuidado com as mulheres e a politização do cuidado}

Entrevistada: Outra questão que considero importante pensar, quando falamos nas atividades e disposições do cuidado, é a questão de gênero. É essa coisa do estereótipo da "mulher-mãe". Trata-se de uma questão que precisa ser enfrentada por nós, enquanto sociedade. Nós produzimos um estereótipo de que o cuidado é uma coisa de mulher, e de que o cuidado precisa ser exercido por uma pessoa próxima da família.

Se eu penso na pessoa que cuida, no momento que ela raciocina e decide, ela pode chegar à conclusão de que não é a pessoa mais indicada para cuidar da outra, naquele momento. Porque ela não está bem com a criança, a pessoa adoentada, o idoso... Ela não consegue fazer aquilo bem ou sabe de outra pessoa poderia fazer algo melhor. Se ela tem a consciência de que não está fazendo bem para ela estar com uma criança menor de cinco anos de idade dentro de casa, mais de 4 horas seguidas. Ela pode até conseguir ir aumentando o grau de tolerância e paciência, ao longo da vida. Mas porque ela é mulher e a pessoa em questão é o filho ou o pai dela, ela é obrigada, pela sociedade, a sublimar praticamente tudo e sacrificar a si mesma! E nossa cultura realmente não permite que a gente nem se aproxime desse raciocínio (de não poder ou não querer assumir sozinha toda a responsabilidade pelos outros no ambiente doméstico). Ele é vetado! E quando esse raciocínio começa, a mulher que o desenvolve pode sentir-se muito mal, moralmente, pensando de si que é um monstro.

Equipe do projeto: Tenho um exemplo próximo. Estes dias, minha mãe voltou de uma visita a uma amiga acamada que precisava de ajuda e a quem minha mãe visita sempre. Ao voltar da casa da amiga, minha mãe fez o seguinte comentário: "Como que a filha dela não pede licença no trabalho pra cuidar da mãe?!!" Eu respondi: "Será que ela pode se afastar do trabalho? Será que ela tem essa disponibilidade? Será que ela quer?’ E minha mãe logo emendou: "E daî? Ela é filha!" Essa cobrança é muito forte, da sociedade. A mulher, e nesse caso é a filha, precisa largar tudo para cuidar de alguém. Isso é uma questão dada de antemão, na sociedade. Até a vizinha dá palpite! 
Entrevistada: Mostra como a questão do cuidado precisa ser politizada e assumida por nós enquanto sociedade.

Equipe do projeto: Penso no papel do Agente Comunitário de saúde que mora no território (no local em que também trabalha), em geral muito próximo, ele mesmo, de uma alta vulnerabilidade. A questão social está ali, presente duplamente para ele, como morador e como trabalhador. Então ele vai lá exercer sua atividade junto a alguém que está desempregado, passando por fome ou sofrendo situações de violência. E não são poucos os exemplos desse tipo. A politização do cuidado tem a ver também com perceber nessa situação e os limites dela e de quem cuida. Apesar de haver uma legislação a respeito das atividades do agente comunitário, ela não é suficiente para, na hora que se está no território, na prática, saber o que fazer. O resultado, muitas vezes, é extremado: o cuidador se mobiliza para arrumar uma cesta básica ou deixa de ir à casa da pessoa a quem não consegue mais auxiliar. A politização é importante também nesse sentido, de você se localizar, de saber qual é o seu papel, o que tem a ver com você. E se você precisa de ajuda.

Entrevista da: Essa questão da profissionalização do cuidado eu ouço muito em um contexto de crítica. É comum ouvir alguém dizer: "Politizar o cuidado? Então agora vamos meter todo mundo em instituições? O cuidado vai passar a ser somente técnico?” Para muitas pessoas é difícil imaginar que o político também pode ser permeado por relacionamentos de qualidade. Para elas, isso parece, então, uma coisa assustadora. E rechaçam, não querem nem dialogar. O cuidado tem de continuar sendo coisa do campo das relações afetivas, não pode ter essa conotação política. Por outro lado, estamos ouvindo as pessoas com deficiência fïsica nos dizendo que elas precisam dessas instituições ou querem essas instituições com alternativa ao que estão recebendo em casa. Não é possível generalizar, claro. Mas há muitas pessoas refletindo sobre isso e chegando a essa conclusão.

Precisamos conversar. Precisamos discutir e elaborar melhor o que é, como fazer, quem são as pessoas que vão trabalhar nessas instituições etc. O perigo é o de uma resposta muito fácil. Quem serão essas pessoas? Mulheres. Por quê????? A resposta é fácil demais: Porque já sabem como as coisas devem ser, nascem sabendo! E não é assim. Por isso essa primeira geração de pesquisadoras da Ética do Cuidado foi composta por feministas. Elas tinham de enfrentar dois problemas: (a) fazer avançar um conceito em um campo de trabalho carregado de preconceito e, ao mesmo tempo, (b) descolar ele das mulheres, como se o cuidado fizesse parte de uma "natureza feminina". O mais delicado de tudo era ter de dizer: "sim, mulheres são nossa melhor fonte de pesquisa sobre o assunto, são as pessoas mais especializadas que temos na sociedade, mas não se trata de uma "coisa de mulher" (no sentido de algo nato)!!! As pesquisadoras enfrentaram os problemas, assumiram as mulheres (que cuidam) como principal objeto de pesquisa e tentaram compreender o que desenvolveram como critério, técnica, raciocínio etc., sem assumir um discurso essencialista.

$A$ verdade é que, quanto mais vocêfaz algo, maior a probabilidade de que você se torne especialista nisso.

Tem uma autora que eu gosto, também filósofa e feminista, que escreveu sobre a "natureza humana". O nome dela é Alison Jaggar (1983). Ela não trabalha com o tema do cuidado, mas critica a sociedade que joga as atividades de cuidado sobre as mulheres (e no doméstico). Ela comenta que, para criar um ser humano até a fase adulta, uma pessoa só não basta! É preciso muito mais gente. $E$, se pensarmos bem, um humano precisa de, mais ou menos, quatorze anos para poder sair por aí na vida. Durante esse tempo todo, precisará de várias pessoas suprindo suas necessidades básicas (por alimento, saúde, moradia, conhecimento...). 
O que acontece é que, em geral, quando grita um bebê, a mulher que o gestou vai acudi-lo porque ninguém foi ou está indo. Principalmente em sociedades como as nossas, que idealizam famílias iniciando em duplas e não em comunidades, com a sociedade dizendo aos homens que quem deve agir nessa situação é a mulher. Em geral, a mulher (que acabou de parir e ainda está se recuperando) é quem vai acudir o bebê que chora. E se ela não vai é considerada "desnaturada", um ser humano "contrário à natureza".

Por que as mulheres acabaram desenvolvendo tantas qualidades relativas ao cuidado? Porque, na verdade, elas é que acabam atuando no sentido de garantir a vida do recém-nascido. Mas é cultural. Nas culturas em que as crianças nascem e não são necessariamente atreladas à pessoa que as pariu, a mãe biológica pode não ser a mais indicada para acudir o bebêe outras mulheres o acodem. Há grupos em que todas as mulheres são "as mães" de todas as crianças ou que homens e mulheres cuidam. O grito desse ser humano recém-nascido é ouvido por mais pessoas e mais pessoas se movem para auxiliá-lo e cuidá-lo.

Tem uma sociobióloga feminista que eu gosto muito, chamada Sarah Hrdy (2001). Uma das perguntas de pesquisa dela é: por que o bebê humano é tão agudamente vulnerável quando o comparamos com os bebês de qualquer outra espécie? A hipótese que ela arrisca como resposta é a seguinte: Imagine um recém-nascido em meio aos grupos nômades. Ele não aguentaria o pique das andanças. Do ponto de vista da evolução, era muito mais importante gritar e sorrir. O que ele tem de fazer é captar (e cativar) um humano adulto. O esforço do bebê humano é o de convencer um adulto de levá-lo junto, de carregá-lo. Então ele vai gritar e vai sorrir. Vai seduzir. O bebê da espécie humana sorri para os adultos disponíveis no ambiente e que ele percebe serem os mais gentis com ele. É uma questão de sobrevivência. O bebê da espécie humana não vai andar, não vai conseguir se alimentar sozinho... Ele joga todo o seu esforço em algo que possa captar um adulto (e não precisa ser sempre o mesmo), se não ele não sobrevive em um grupo nômade. É interessante.

A gente fala das famílias e estamos tão habituados a pensar na mãe biológica, mas às vezes não é ela que acode ou que tem o "favoritismo" do bebê. Pode ser a avó, a tia, a vizinha. Em geral é uma mulher que age com benevolência e paciência para com o bebê, e ele capta alguém. Não precisa ser a mãe biológica, ainda que muitas vezes seja somente ela a disponível ou seja ela que todos "empurram" para assumir o bebê nos momentos mais críticos. De qualquer modo, mulheres costumam reagir ao fato de estarem diante de um ser em uma situação de dependência aguda, de uma incapacidade de sobrevivência assustadora.

Voltando à questão da politização do cuidado, a pergunta agora seria assim: Como criar uma sociedade na qual todas as pessoas adquirem as habilidades de cuidar? Ou como distribuir melhor essas atividades? Se as tivéssemos mais bem distribuidas e uma quantidade boa de pessoas que desenvolvem as qualidades de cuidado, vamos então ter uma sociedade que será muito melhor, em seu todo. As instituições poderiam ter pessoas que já treinaram o cuidado em suas relações pessoais, cuidando e sendo cuidadas. Serão pessoas atentas, com muitas das características que podemos qualificar como necessárias às boas práticas de cuidado e que incluem a si mesmas nas redes de cuidado, sem precisarem assumir tudo sozinhas. 


\section{Notas}

1 Comunidades Eclesiais de Base. Comunidades organizados e ligadas principalmente à Igreja Católica que se multiplicaram pelo Brasil e pela América Latina nas décadas de 1970 e 1980 para discutir e enfrentar problemas em comum, como a miséria e a falta de políticas públicas adequadas.

2 Suas pesquisas mais recentes focam nas práticas médicas. Sua compreensão do cuidado está atrelada a questões práticas tanto quanto teóricas, sendo o seu foco as interações entre médicos, enfermeiras e familiares com as pessoas que enfrentam a Diabete, a arteriosclerose ou a anemia (por exemplo). Para essa filósofa, conhecer é algo que resulta do engajamento e da intervenção nas práticas, no ponto em que elas criam realidades.

3 Pesquisadoras como Carol Gilligan, Sara Ruddick e Nel Noddings, por exemplo.

4. Na associação entre cuidado e amor uma série de questões ficam "escondidas", como: a exploração das mulheres para o cuidado de todas as pessoas do seu núcleo familiar e a extensão disso para o cuidado de todas as crianças, todos os idosos, todos os doentes... da sociedade; o ataque às mulheres que não querem ou não se sentem confortáveis em cuidar de outras pessoas; a fuga dos homens da responsabilidade de cuidar de suas companheiras, seus familiares e pessoas de fora do círculo familiar etc.

5 Carol Gilligan (1982), por exemplo, apontou para a importância da busca por soluções adequadas a cada caso envolvendo práticas de cuidado e para a necessidade de preservação das relações sociais das pessoas nelas envolvidas. Gilligan também deu o pontapé inicial para definir algo como um cuidado maduro (que, para ela, estabelece um equilíbrio entre cuidar-de-si e cuidar-dos-outros). Nel Noddings (1984) enfatizou a complexa estrutura de memórias, sentimentos e capacidades envolvidas nos raciocínios do cuidado. Suas definições de cuidado natural e cuidado ético foram igualmente importantes. Sara Ruddick (1989) e Virginia Held (1987), por sua vez, trabalharam com a ideia de cuidado como atividade (um tipo de trabalho ou um conjunto de práticas) envolvendo relações humanas desiguais e pessoas interdependentes. Rudick defendeu que há um tipo de raciocínio por trás das práticas de cuidado que envolve a preservação da vida, a manutenção e o desenvolvimento físico, intelectual e emocional da pessoa cuidada, assim como o seu treino para viver em sociedade. E há outras pesquisadoras a serem citadas.

6 Representante do que é considerada a segunda geração de pesquisadoras do cuidado.

7 Essa questão é mais explorada no artigo: Zirbel, Ilze (2020). Cuidado, Masculinidades e Responsabilidade Social. Revista Mais que Amélias, 7, 1-24. Dossiê Especial Ética do Cuidado. Recuperado de https://8817bea9-051e-4071-aa02-bboea330c83e.filesusr.com/ ugd/cafbb5 eaafd0741 1 cof4d4899b325efeaaedabc.pdf 
8 A questão da autonomia aplica-se àquelas pessoas que podem vir a experimentar algum grau de autonomia. Há, porém, pessoas que não vão experimentá-la ao longo da vida, como é o caso das pessoas com deficiência mental grave, ou que terão um grau bastante reduzido de autonomia física ou mental. Para estas, o grau de autonomia que podem exercer deve ser respeitado.

9 Os Disability Studies são um campo de pesquisa que examina o significado, a natureza e as consequências da deficiência em nossa sociedade. Muitas palavras foram usadas para substituir o termo "deficiência”, mas esse campo optou por usá-lo, fazendo uma diferença entre a pessoa que tem uma deficiência física ou mental e a maneira como a sociedade a vê e descreve.

\section{Referências}

Boff, L. (1999). Saber Cuidar. Ética do humano - compaixão pela terra. Petrópolis, RJ: Vozes.

Boff, L. (2005). O cuidado essencial: princípio de um novo 'ethos', Inclusão Social, 1(1),28-35.

Engster, D. (2007). The Heart of Justice. Care Ethics and Political Theory. Oxonia, UK: Oxford University Press.

Gilligan, C. (1982). Uma voz diferente. Psicologia da diferença entre homens e mulheres da infância à fase adulta. Rio de Janeiro: Rosa dos Tempos.

Held, V. (1987). Feminism and Moral Theory. In N. A. S Jecker, A. R. Jonsen, \& R. A. Pearlma (Eds.), Bioethics: An Introduction to the History, Methods, and Practice (pp. 158-163). Ontario/ London: Jones and Bartlett Publischers.

Hrdy, S. B. (2001). Mãe Natureza - uma visão feminina da evolução: maternidade e seleção natural (A. Cabral, trad.) Rio de Janeiro: Editora Campos.

Jaggar, A. M. (1983). Feminist Politics and Human Nature. Nova Jersey: Rowman \& Allanheld Publishers.

Mol A. (2008). The Logic of Care: Health and the Problem of Patient Choice. New York: Routledge.

Noddings, N. (1984). Caring: A Feminine Approach to Ethics and Moral Education. Berkeley: University of California Press.

Ruddick, S. (1989). Maternal Thinking: Toward a Politics of Peace. Boston: Beacon Press.

Silvers, A. (2015). Becoming Mrs. Mayberry: Dependency and the Right to be Free. Hypatia, 30 (1), 292-299. https://doi.org/10.1111/hypa.12133

Tronto, J. C. (1993). Moral Boundaries. A Political Argument for an Ethic of Care. New York: Routledge. 
CARLOS ROBERTO DE CASTRO-SILVA

https://orcid.org/0000-0002-8880-1042

Professor Associado da UNIFESP- Instituto Saúde e Sociedade/ Departamento de Politicas Publicas e Saúde Coletiva e Professor orientador do Programa Interdisciplinar em Ciências da Saúde. Pós doutorado em Ciências Sociais na University of Western Ontario-Canadá. Doutorado em Psicologia Social no Instituto de Psicologia da USP. Mestrado em Psicologia Social da PUC/SP. Especialização em Saúde coletiva pela Faculdade de Medicina- USP.

E-mail: roberto.castro@unifesp.br

\section{DANILO DE MIRANDA ANHAS}

https://orcid.org/O000-0001-6842-7156

Professor Doutor nas Faculdades Integradas Campos Salles, Doutor e Mestre em Ciências da Saúde pela Unifesp/Baixada Santista.

E-mail: danilo-anhas@hotmail.com

\section{KARINA RODRIGUES MATAVELLI ROSA}

https://orcid.org/0000-0001-7609-1402

Consultora em Políticas Públicas. Doutora e Mestre em Ciências da Saúde pela Universidade Federal de São Paulo/Baixada Santista.

E-mail: karina to@hotmail.com

\section{LAIÍS HELENA DUTRA}

https://orcid.org/0000-0002-5047-8905

Mestra pelo Programa de Pós-graduação Interdisciplinar em Ciências da Saúde na Universidade Federal de São Paulo (UNIFESP), Especialista em Saúde Pública pela Fundação Escola de Sociologia e Política de São Paulo (FESPSP), Docente na Universidade Cidade de São Paulo (UNICID) na disciplina de Atenção Primária à Saúde na graduação em Medicina.

E-mail: dutra_lais@hotmail.com

\section{LIA THIEME OIKAWA ZANGIROLANI}

https://orcid.org/O000-0002-9966-5701

Professora Associada do Curso de Nutrição e do Eixo Trabalho em Saúde, Departamento de Políticas Públicas e Saúde Coletiva do ISS/UNIFESP-BS.

E-mail: lia.oikawa@unifesp.br

\section{LUCIANE MARIA PEZZATO}

https://orcid.org/O000-0002-3591-1491

Pofessora adjunta do Eixo Trabalho em Saúde, Departamento de Saúde, Clínica e Instituições - Instituto Saúde e Sociedade - Universidade Federal de São Paulo, Campus Baixada Santista - ISS/UNIFESP-BS.

E-mail: luciane.pezzato@unifesp.br 


\begin{tabular}{|l|l|}
\hline \multirow{2}{*}{ Histórico } & $\begin{array}{l}\text { Sulbmissão: 24/05/2020 } \\
\text { Aceite: 23/09/2020 }\end{array}$ \\
\hline \multirow{3}{*}{ Financiamento } & $\begin{array}{l}\text { Ética do cuidado e construção de direitos: acolhimento psicossocial em } \\
\text { práticas da saúde da família em situações de exclusão social - Fapesp no. } \\
2016 / 23973-2 .\end{array}$ \\
& $\begin{array}{l}\text { Desigualdade social e subjetividade: trajetórias de vida e lutas por } \\
\text { melhores condições de vida e saúde em território vulnerável da Baixada } \\
\text { Santista - CNPq no. 407836/2016-0. }\end{array}$ \\
\hline
\end{tabular}

